\title{
Instruction Of Competent Psychomotor Skill
}

\author{
Valerie Dong Olson, Seton Hall University, USA
}

\begin{abstract}
Instruction of competent psychomotor skill necessitates an eclectic approach. The principles of learning, complemented with learning styles and sensory modalities preferences, provide a background for teaching physical skills. The use of the psychomotor domain of Bloom's Taxonomy as a map and corresponding behavioral objectives foster the mastery of competent psychomotor skills. Finally, the choice of instructional strategies and teaching methods enhances the efficacy of instruction of competent psychomotor skills, in addition to student learning assessment, instructor feedback, and student reflection of learning.
\end{abstract}

Keywords: Instruction, Competency, Psychomotor Skill

\section{INTRODUCTION}

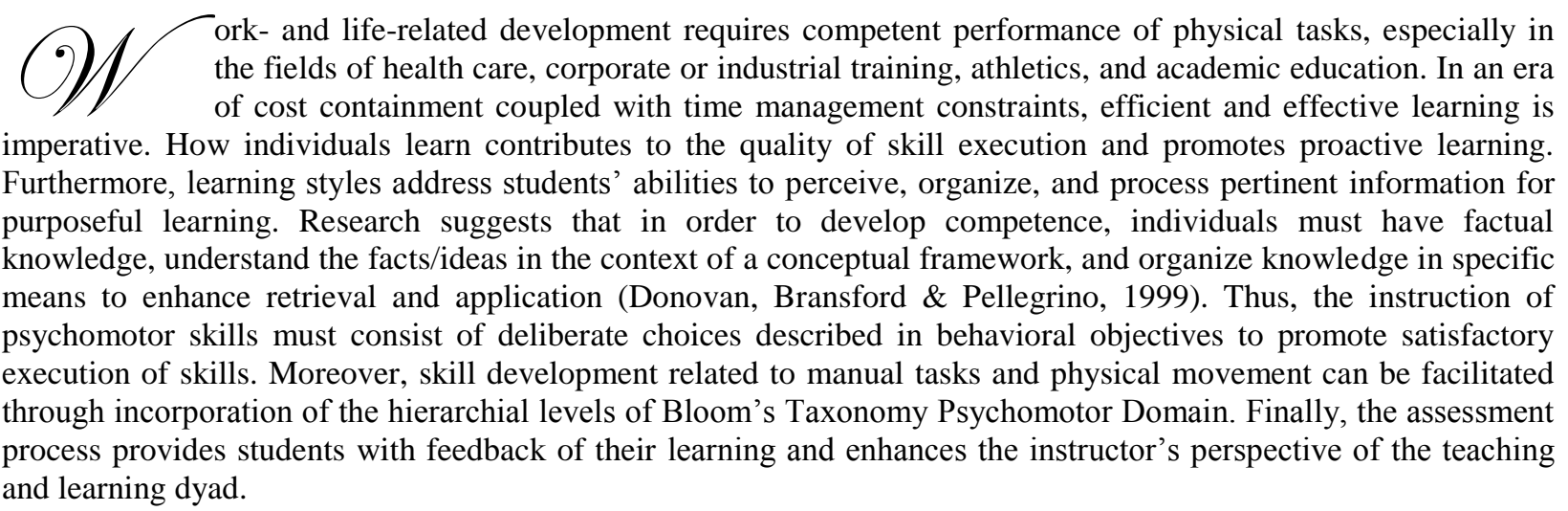

\section{LEARNING TO LEARN}

According to Driscoll (2002), there are four principles of learning. First, learning occurs in context, or within the appropriate setting. Second, learning is active, where the emphasis is that learners need to be mentally active, develop relationships between new and existing knowledge, and establish connections from an individual's own experiences. Third, learning is social, and collaboration with others affords experiences to learn of perspectives and achieve the learning task with the assistance of peers and experts. Finally, learning is reflective, and the provision of internal assessment of the learning experience enhances one's own expression and thinking. Encompassing these principles in the teaching of psychomotor skills fosters optimal learning.

The following scenario serves as an example. An individual is visiting New York City for the first time and has never experienced riding on a train. In New York City, the main mode of public transportation is the subway, which is composed of hundreds of miles of underground tracks that intertwine and provides access to all five city boroughs. First, the context or the appropriate setting is riding a train to be transported from uptown to downtown to the Staten Island Ferry. Second, the active learning where the visitor's cognitive processes subconsciously or consciously relates this new experience to a past movement and/or knowledge scenario. The visitor may make a connection to sitting on a moving horse, riding a tractor, or standing on a moving bus. Third, the visitor is accompanied by a tour guide who provides information on the subway as the train doors opens and suggests sitting at the far end of the train where there are available seats. However, the train doors quickly close and the visitor is 
challenged to walk on the train while it is in transit and move to the far end. As the visitor is walking, the moving platform of the train makes it difficult to maintain a straight path and the visitor soon learns how to walk forward without stepping on anyone's feet. The visitor is experiencing different skills as he is jostled as the train moves around a bend and comes to a screeching halt forcing the visitor to grab a nearby pole for stability. The visitor lunges towards the opening door to disembark the train and reflects upon the unique experience. Although hesitant to ride the train again, the visitor enjoyed the ride and reflected on how the "country" gentleman was able to manage the city public transportation. The visitor experienced Driscoll's principles of learning in mastering the psychomotor skills of upright balance while riding the moving subway train.

\section{MULTIDIMENSIONAL LEARNING}

Learning is complex and requires multiple approaches. In general, three learning styles consist of visual, auditory, and kinesthetic, which combined is commonly labeled as VAK (Clark, 2000; Murphy, Gray, Straja \& Bogert, 2004). This approach complements the Driscoll's principles of learning, however from an individualistic aspect. The learner relies upon the sensory information in the surroundings for learning. Visual learners depend on seeing and looking, and the first access to learning is the intent gaze and the use of vision to interpret items, actions and changes with the environment. Visual learners are able to see and select specific cues essential to deliberate learning. Whereas auditory learners primarily rely on hearing and listening, as demonstrated when one tilts the head to "listen" to the changes of sound or voice. Auditory learners may even close their eyes to concentrate on the sounds or voices heard. Kinesthetic learners learn through the sense of touch and by doing, and these learners tend to be "movers". They innately understand their body in space and as it moves, execute tasks with ease and skilled coordination. Individuals may have a stronger disposition in one or more styles. Depending upon the demands of the psychomotor task, one may modify the predominant sensory system or change modalities.

Let's return to the visitor who had just experienced his first ride on the New York City subway. Learning also encompassed integral components, VAK. While entering the train, the use of vision was needed to ascertain the size of the space between the station platform and the train floor in order to step into the train. The visitor needed to see where he was going and focus on the seat located at the end of the train. Auditory learning may have been compromised as there is a great deal of noise, with the train he was riding on and other passing trains stopping and accelerating creating deafening auditory chaos. Using kinesthetic learning, the visitor practiced various balancing options to maintain upright, such as stepping forwards, backwards, sideways, and in diagonals to ultimately arrive at his desired location. The steps were fast and slow, small and large. His body, arms and head follow in various directions, the same as his feet or in the opposite direction of his feet. Meanwhile, there is characteristic chugging vibration throughout the ride, magnifying the intensity of kinesthetic "feeling" of the ride. The visitor was ultimately successful in the interpretation of VAK sensory information to produce a purposeful and satisfactory movement outcome, balancing and maintaining upright while riding on the training. Integrated with Driscoll's learning principles, individual sensory processing provides a broader multidimensional approach to learning psychomotor skills.

Standard inventories of learning styles also exist, such as the Kolb Learning Style Inventory and the Gregorc Style Delineator (Olson and Scanlon, 2002). These inventories, which have been subjected to statistical analyses, provide individual learning profiles in relation to perception, organization, and process of the task and environment. The outcomes may be used to provide direction of primary styles of learning, and can provide a basis for further dialogue in areas to reinforce and areas to grow. For example, in assembling a computer for the first time, does the learner need to experience the task of assembly first, to listen to sequential directions first, or to read the end result first and look at a picture of the finished product?

In learning, it is essential that the learner and instructor understands the why, how, when, where questions and be allowed to absorb the information using one's preferences within the context of the goals. The instructor is responsible to select the optimal instructional strategies and teaching methods in order achieve the learning outcomes. Understanding the various aspects of learning and teaching psychomotor skills provides support in the selection and use of training in light of the learner, task and environment. 


\section{MAPPING AND ALIGNING PSYCHOMOTOR LEARNING WITH OUTCOMES}

Instructional strategies and teaching methods are instrumental to match learning styles or mismatch learning styles to foster abilities to "stretch the comfort zone" and "think outside of the box." In teaching and training, Bloom's taxonomy consists of three divisions, one of which specifically addresses the psychomotor domain. Although this domain was developed after the familiar domains (cognitive and affective), it is considered an integral part of the holistic perspective of learning (Bloom et al, 1956). There are three models of the psychomotor domain; however, the Simpson interpretation (Simpson, 1972) of the psychomotor domain is used primarily because it displays two additional levels prior to the initial imitation or copy stage. Simpson's first two levels, perception and set, provide preparatory levels as prerequisites to the development of a physical task. The classification of educational objectives in the psychomotor domain consist of seven levels: perception (awareness), set (readiness), guided response (attempt), mechanism (basic proficiency), complex overt response (expert proficiency), adaptation (adaptable proficiency), and origination (creative proficiency). Bloom's taxonomy is an essential tool for the development, instruction, and evaluation of vital physical skills.

Once again, the following serves as an example. The visitor scenario is now adapted to how to learn to ride the New York City subway train for the first time. However, while riding the long escalator down to the train platform, the visitor loses his glasses leaving him legally blind. This now creates a dilemma as the initial learning experience will need to be modified as the visitor is unable to use his vision to walk and locate his seat at the far end of the train. With that in mind, his tour guide, concerned for his safety, takes a different approach to assist the visitor's learning now without vision. Using Driscoll's principles of learning, the guide first provides a description of the context of the setting. The subway train has arrived, the doors have opened and they have a few seconds to walk to and enter the train, after which they will find the first available seat on the crowded train. Since the learner has had an initial experience riding the train, he will use some of the learning to comply with the plan. With nervous laughter, he reaches for the guide's arm for support and direction and continually engages in a conversation by asking numerous questions of what was happening. As the doors close behind them, the two in tandem walk to the middle of the train. The visitor finds himself automatically bending his knees, separating his feet so that they are placed wide apart, and hesitating to step and does so only when there is less noise and minimal jostling by the train movement. The guide explains that there is a small space on the bench for him to sit. The guide helps him to turn and sit in the small space. The visitor reflects and assesses the new learning of the compromised psychomotor task of dynamic balance and maintaining upright in the train. The scenario encompasses the learning principles. In addition, the visitor noted in his assessment how some of his strategies in using his senses were augmented. The vision was compromised, so the visitor did not use the important sense to execute the task. The incessant conversation and train noises provided additional input for auditory learning of the scenario. Kinesthetic cues throughout the movement facilitated a successful entrance and access of a seat. Some of the cues consisted of the use of the guide's arm for guidance, and his own changing body positioning in response to the train movement. With the modified scenario where the visitor's vision was compromised, the principles and styles of learning were evident in the learning of the challenging psychomotor skill.

The seven levels of the psychomotor domain are present in the modified scenario. Perception (awareness) and set (readiness) are noted in the preparatory activities by the guide and visitor. The visitor demonstrated guided responses (attempt) in performing the revised skill set, and he was able to exhibit the mechanism (basic proficiency) of balance and maintaining the upright position while being jostled. As time passed and the visitor rides the subway train again, the complex overt response (expert proficiency) would be revealed if and when he is able to walk in the moving train with adequate balance while maintaining upright, despite the compromised vision. In addition, the visitor would be able to demonstrate adaptation (adaptable proficiency) should he ride the subway train during rush hour when the walking area would be narrower and have numerous obstacles (other riders). Origination (creative proficiency) may occur when the visitor is able to walk on the moving Staten Island Ferry, a task which affords different sensory stimuli and environment. The hierarchy of Bloom's Taxonomy provides a "map" to learning and aligns the learning with the outcomes-competent psychomotor skills. 


\section{COMPETENT PSYCHOMOTOR SKILL}

Competence in the performance of psychomotor skills mandates clear expectations, communicated through clear and concise behavioral objectives. Forrest (2003) believes that good training design begins with setting good learning objectives. An objective defines the action of the student and, in general, describes the method of instruction and the criteria for the learner outcome. A SMART objective focuses on S for specific, $\mathrm{M}$ for measurable, A for attainable, $\mathrm{R}$ for results-focus, and $\mathrm{T}$ for timely (Forrest, 2003). The ABCD method of writing objectives (Heinich et al., 1996) addresses four components: A for audience or who the learner is, B for the expected behavior, $\mathrm{C}$ for the condition or context of learning, and D for degree of mastery. Specific to the psychomotor domain, key verbs to delineate the desired behavior correspond with the seven levels. This allows students to climb the "ladder" of learning physical skills.

Linking the objectives to assessment is an essential aspect to determine whether students have demonstrated mastery of the psychomotor skill. The use of checklists for instructor, peer, and self to provide written feedback is important in the triangulation of evaluations. In addition, the use of video in recording the entire performance, to monitor the students' execution of physical tasks as well as verbal and nonverbal communication, is another advantageous tool for feedback. The timing of the provision of feedback is essential for students to recall their performance through their visual, auditory, and kinesthetic senses. It would be beneficial to also address the standard learning styles to determine the match or mismatch of the students' learning to the instructor's choice of instructional strategies and teaching methods. Instructor evaluation of the learning process is also necessary to ascertain the advantages and disadvantages, as well as to substantiate if any modifications of the process are warranted.

\section{CONCLUSION}

Satisfactory performance of psychomotor skill is expected within the daily routine and is embedded within the integral components of work- and life-related development. The instruction of competent skill performance encompasses an eclectic approach, consisting of a triad of the learner, psychomotor task, and environment. It is essential to incorporate various styles of learning and teaching psychomotor skills, as well as to document mastery through the use of specific behavioral objectives. This paradigm provides a practical approach to instruction in psychomotor skill development and competence.

\section{REFERENCES}

1. Bloom, Engelhart, Furst, Hill, Krathwohl, (1956). Taxonomy of education objectives. Allyn \& Bacon. Boston, MA.

2. Clark, D. (2000). Visual, auditory, and kinesthetic learning styles (VAK). Retrieved 11/12/2007 from http://www.nwlink.com/donclark/hrd/styles/vakt.html

3. Donovan, M., Bransford, J. \& Pellegrino, J. (Eds). (1999). How people learn: Bridging research and practice. National Academy Press, Washington, DC.

4. Driscoll, M. (2002). How people learn (and what technology might have to do with it). Retrieved 11/27/2007 from http://www.ericdigests.org/2003-3/learn.htm

5. $\quad$ Forrest, C. (2003). Writing training objectives using SMART. Train the Trainer.

6. Heinich, R., Molenda, M. Russell, J., Smaldino, S. (1996). Instructional Media and Technologies for Learning. Englewood Cliffs, NJ: Merrill.

7. Murphy, R., Gray, S., Straja, S. \& Bogert, M. (2004). Student learning preferences and teaching implications. J Dent Educ,68:859-66.

8. Pennsylvania State Research on Teaching, Learning \& Technology. How to write clear objectives. Retrieved 11/12/2007 from http://tlt.its.psu.edu/suggestions/research/Write Objectives.shtml

9. Pennsylvania State Research on Teaching, Learning \& Technology. How People Learn. Retrieved 11/12/2007 from http://tlt.its.psu.edu/suggestions/research/How_People_Learn.shtml

10. Olson, V. \& Scanlon, C. (2002). Physical therapy students' learning styles and their teaching method and instructional activity preferences. J Phys Ther Educ,16:24-31.

11. Simpson, E. (1972). The classification of educational objectives in the Psychomotor domain. Volume 3, Washington, DC: Gryphon House. 